American Journal of Pharmaceutical Education 2019; 83 (6) Article 6899.

\title{
RESEARCH
}

\section{Development, Implementation and Assessment of a Comprehensive Strategic Plan in a School of Pharmacy}

\author{
Bhaskara R. Jasti, PhD, John C. Livesey, PhD, Phillip R. Oppenheimer, PharmD, Eric G. Boyce, PharmD \\ Thomas J. Long School of Pharmacy and Health Sciences, University of the Pacific, Stockton, California \\ Submitted December 4, 2017; accepted March 26, 2018; published August 2019.
}

Objective. To develop, implement and assess a strategic plan and its process within a school of pharmacy.

Methods. The process for developing the strategic plan included five phases: designing and scanning by a planning committee; divergent thinking with input from key internal and external stakeholders who shared their vision for the school; convergent planning in which faculty members helped to prioritize the clusters, goals, and metrics that had been identified; refining ideas into strategies; and assessment, during which metrics were aligned with assessment plans and data were collected and analyzed.

Results. The completed strategic plan had five broad strategies, 20 specific goals, and 90 associated metrics. The plan was implemented with engagement by all major stakeholders in the program. Reallocation of existing resources and generation of new resources were key in making progress. The assessment, which was conducted three years after implementation of the strategic plan, found that each strategy had affected the school's mission to provide an exemplary educational experience for students and to advance the institution.

Conclusion. The strategic plan provided direction and focus to meet the challenges of continuing to advance the school. The keys for success in strategic planning are having a well-defined process, involving all faculty members and other key stakeholders, implementing the plan, and routinely assessing progress in meeting the strategic goals.

Keywords: strategic planning, planning, resource allocation, continuous improvement

\section{INTRODUCTION}

A strategy is a long-termplan of action designed to achieve a particular goal. The aim is to realize the goal by following a deliberate pattern of behavior over time ${ }^{1}$ Strategy can be used to set direction, focus effort, define the organization, and provide consistency. Recognizing and embedding emergent elements is important in strategic planning, which can take different forms. Strategic planning has been defined as "a systematic process through which an organization agrees on-and builds commitment among key stakeholders to-priorities that are essential to its mission." "Similarly, others have described strategic planning as "a formal process designed to help an organization identify and maintain an optimal alignment with the most important elements of its environmental set." 3

Corresponding Author: Eric G. Boyce, Thomas J. Long School of Pharmacy and Health Sciences, University of the Pacific, 3601 Pacific Ave., Stockton, CA 95211. Tel: 209-9463144. E-mail: eboyce@pacific.edu
Strategic planning should serve as an adaptive, longterm course of action for an institution for the purpose of improvement. ${ }^{4}$ Such a plan must possess a set of specific, interconnected human, technological, and organizational capacities to achieve these strategic directions. These capacities also require changing academic and administrative processes, aspects of the culture, and behaviors of executive leadership, faculty, and staff. Some of the changes may be achieved quickly while others will take more time. Resources and the inclusion of multiple perspectives, processes, and incentives are necessary contextual elements in strategic planning. A well-focused strategic plan with inclusive input of all stakeholders helps a school or college leverage and possibly reallocate existing resources (including people, budgets, and facilities) to achieve the goals and initiatives of the plan. ${ }^{4}$ By including all pertinent stakeholders in the process, redirecting and building resources will be supported by those involved in the development of the plan. A well thought out plan with metrics for assessment can provide persuasive rationale and justification to central university administration when requesting additional resources, 


\section{American Journal of Pharmaceutical Education 2019; 83 (6) Article 6899.}

especially if the school plan is consistent with a university plan, and also to potential donors when strategies are consistent with their values and goals.

An effective strategic plan must include the mission and vision of an institution. In higher education, strategic planning has evolved from planning mostly for physical facilities of the campus to the current use as a rational tool for orderly and systemic advancement of the academic enterprise. ${ }^{5,6}$ Demographic shifts, technological advances, and educational costs have outpaced the inflation driving this evolution. Strategic planning in higher education is challenging to accomplish, at least in part because it has few rewards available to bring about the necessary changes. ${ }^{7}$ Many times, administrators and faculty members are unsure of the process, even when they acknowledge the need for a strategic plan. ${ }^{8}$

The accreditation standards for the Doctor of Pharmacy (PharmD) degree from the Accreditation Council for Pharmacy Education (ACPE) include the need to perform strategic planning. ${ }^{9}$ The pharmacy education literature includes reports on the development of a continuous quality improvement process for a pharmacy program as a whole based on prior strategic planning, ${ }^{10}$ the use of strategic planning in an academic unit within a college of pharmacy, ${ }^{11}$ and the use of strategic planning in the development of a satellite campus and an interprofessional education program. ${ }^{12,13}$ There are also a limited number of reports of strategic planning and its impact in other health care educational programs and in academic health centers. ${ }^{14-17}$ All of those reports are very helpful, but none address the methods and outcomes associated with strategic planning performed at the program level to address the major components of a college or school of pharmacy.

There are no standardized methods for performing strategic planning. Instead, there are a series of fundamental components that should be included in strategic planning. Strategic planning methods must meet the needs, expertise, and structure of the entity performing the planning, including alignment with the strategic plan and strategic planning process of the parent organization. Strategic planning for a college or school within a university is typically done through an executive committee or a steering committee with input from key individuals to keep the process well organized, inclusive, and well aligned with the university's strategic plan and strategic planning process. ${ }^{10}$

The purpose of this report is to share the process used to develop Pacific 2020, the strategic plan for the PharmD program at the Thomas J. Long School of Pharmacy and Health Sciences to assist other colleges and schools to develop their strategic planning process with a focus on meeting the fundamental components of a strategic plan.
Additionally, three years after implementing the plan, we assessed our progress using the outcomes we had outlined. In addition to describing the process for forming the strategic plan, in this paper we share the findings from our assessments and provide lessons learned. The goals are to assist others in the development and implementation of their own specific strategic plan and appropriate metrics which are designed to meet the needs of their program, academic unit, and parent institution.

\section{METHODS}

The University of the Pacific is a nationally ranked university with three distinct campuses united under one common goal: to educate and prepare the leaders of tomorrow through intensive academic study, experiential learning, and service to the community. The Thomas J. Long School of Pharmacy and Health Sciences is located on the Stockton campus, and has provided innovative programs and extensive leadership opportunities to students from around the world. The mission of the school is to prepare students for lifelong success in health careers by providing an excellent, student-centered learning environment. We aspire to develop leadership skills in students and a strong commitment to their professions, to interprofessional collaboration, and to society. These efforts are assisted by linkages between the university's professional and liberal arts programs. We support outstanding professional and graduate teaching, research and other scholarly activity, and services as a means of achieving our mission. The school adapts its programming alongside the ever-evolving health care industry. To comply with ACPE accreditation standards and to continue to advance our curriculum, programs, research, and community outreach initiatives to stay a step ahead of the industry landscape, the dean initiated a strategic planning process in 2012 entitled Pacific 2020.

The Strategic Planning Committee, a nine-person ad hoc group reporting to the dean, served as the central coordinating body for the development of the strategic plan. The committee included multiple members from each of the three academic departments and an administrative staff member. Each member of the committee was expected to serve the needs of the school and the program as a whole, rather than serve the needs of a specific department or office. The committee established the following goals upon receiving its charge to develop a strategic plan: define the school's core values, assess current processes, identify future trends, establish strategies and goals to educate students, and assess the effectiveness of the plan periodically. An additional goal of the plan was to align the strategic plan for the school with the strategic plan of the university. The strategic plan was 


\section{American Journal of Pharmaceutical Education 2019; 83 (6) Article 6899.}

designed to be dynamic and adapt to change. To succeed in the development and implementation of the plan, the committee designed an inclusive approach where all stakeholders (faculty, staff, alumni, executive leadership, etc.) participated in the process. For the purposes of this strategic plan, a strategy was envisioned to be a general description of several interconnected goals that could be accomplished over the duration of the plan, and a goal was a well-defined effort to achieve a certain outcome. Metrics were designed to assess the outcomes of a goal with multiple measurements. The strategic planning committee divided the planning process into the five phases described below.

Phase 1: Designing and Scanning was conceptual and focused on the pre-work necessary to launch a successful planning process. The objective of this phase was to examine the existing value statements of the school and the assumptions regarding the direction of the school, and to design a planning process that enabled the reconsideration of these elements in the context of potential future developments.

Activities during the design and scanning phase also focused on how the new strategic planning process aligned with university planning and change-related activities, and how to manage and assess that alignment. The first phase of the strategic planning process also focused on scanning the environment for key factors influencing the PharmD program at that time and in the future. Knowledge and information was gathered on the following factors: political/community, economic/competitive, social/ demographic, technology/teaching, learning and scholarship, and environmental factors affecting higher education, specifically those related to the pharmacy profession and accreditation guidance. These knowledge and information resources were made available in a repository to support the work of the planning groups and were accessible to all faculty and staff members. Also, each administrative office was asked to provide a preliminary strengths, weaknesses, opportunities and threats (SWOT) analysis related to their responsibilities within the school.

Phase 2: Divergent Thinking was highly participatory and consisted of a "bottom-up" approach for strategy generation. In this phase, the existing values, assumptions, and offerings were discussed in the context of the possible futures that the school might confront. Future conditions, challenges, opportunities, and alternatives were explored. This phase was guided by the program's statements of values and principles, the Environmental Scan provided by internal experts, documents from external professional and educational entities [eg, American Association of Colleges of Pharmacy (AACP), American College of Clinical Pharmacy (ACCP)], input from alumni, and the SWOT analyses provided by each department, administrative officers, and those in professional leadership positions. During this phase, all participating individuals were asked to consider the evolution of the profession for the next 20 years and how to train future professionals to navigate the changes in the profession and health care they would face.

Phase 3: Convergent Planning was a "quieter" phase of the strategic planning process in that it primarily involved members of the Strategic Planning Committee who were tasked with weaving together the many threads put forward in the Divergent Thinking Phase. Phase 3 was focused on developing possible solutions, strategies, and decisions. These were clustered and incorporated into a first draft of the strategic plan. All the opportunities that were presented in the divergent thinking process were clustered into five cohesive groups, each cluster having 12 potential goals formulated by the strategic planning committee. These clusters were presented to faculty members at a retreat at which all on-campus faculty members participated, with the exception of two members who were on sabbatical leave. During this meeting, faculty groups discussed the clusters and potential goals and metrics, and prioritized them into five potential strategies, each with five to six goals.

Phase 4: Refining involved continued refinement of the strategic plan with a description of each strategy, and the creation of a strategic financial plan aligned with the strategic plan. The spirit of this phase was refinement and detailing of plans by the strategic planning committee, with input from the dean and dean's cabinet members. Consultations with external constituencies (eg, alumni board, dean's leadership council) were also sought. The focus was on providing measures for effective and flexible execution of strategies. Finally, the developed plan was reviewed with the university's strategic plan to ensure that priorities aligned.

Phase 5: Assessment consisted of refining the metrics and supporting analytics necessary to enable strategy execution and capacity building. The metrics were crossreferenced and aligned with the school's assessment plan to ensure agreement and synergism. The goals of the assessments were to determine the progress and impact made by each strategy on the pharmacy program.

Implementation of the strategic plan began during the development and approval stages of the strategic plan, which was followed by full implementation within 12 months after approval of the strategic plan. Faculty committees, academic departments, and administrative offices, where appropriate, were engaged in implementation of the strategic plan. Faculty meetings included discussions related to the implementation and the progress made on the 


\section{American Journal of Pharmaceutical Education 2019; 83 (6) Article 6899.}

strategic plan. The assessment of the strategic plan was incorporated into the school's assessment plan, including all strategic goals and metrics. Assessment data were collected each year and reviewed. At the end of three years, assessment data for each strategic goal were then aggregated to evaluate the progress on each strategic goal.

\section{RESULTS}

The final strategic plan approved by the faculty had five major strategies and each strategy was associated with three to five specific goals (Table 1). The plan aspired to achieve 20 goals over a seven-year period. The five strategies were as follows: 1. enhance pharmacy student abilities and learning through curricular innovation, integration, application and assessment; 2 . enhance pharmacy students' academic and professional success; 3 . build, expand and sustain community service and scholarship; 4. strengthen partnerships with internal and external constituencies to maximize Pacific's competitiveness; and 5. recruit, develop, retain, and support exceptional faculty and staff in fulfilling their roles and responsibilities.

The five major strategies, the abbreviated strategic goals, an example of a metric identified for each strategic goal, and the general outcomes for each metric are provided in Tables 1-5. The status of the expected metric for each goal was assessed as one of the following: exceeded, met, on course, or metric needs revision (when it was difficult to collect assessment data).

Each strategy and each goal in the strategic plan was paired with one or more measurable metrics to determine whether the listed goal was achieved. This permitted assessment of the outcomes of the strategic plan in a transparent way. Our strategic plan had a total of 90 metrics to evaluate the 20 goals spread over five strategies.
The aim of the plan was to fulfill all the goals by the year 2020. Since this strategic plan is a living document, we assessed the goals at the end of the $3^{\text {rd }}$ year.

As shown in Table 2, of the 90 metrics we listed, we exceeded 29, met 29, and were approaching the goal for 21 others. For the remaining 19 metrics, we either did not have data or the metric needed to be revised.

Strategy 1 had considerable impact on the design and delivery of the curriculum by expanding active-learning methods across the curriculum, enhanced curricular mapping to ensure appropriate content coverage and sequencing, and enhanced communication among faculty members to enhance integration of content. Additionally, methods were used to ensure high passage rates on the North American Pharmacist Licensure Examination (NAPLEX) and to enhance student participation in conducting, presenting, and publishing research. Progress in this strategy also provided a solid base and rationale for upcoming curricular revision.

Strategy 2 was to enhance pharmacy students' academic and professional success, refocused faculty and administrative support on student academic success, career planning, and graduate placement. The opening of the Office of Academic Success and Instructional Support (OASIS) was a major development supported by this strategy. Services offered by OASIS include individual and personal meetings with its director, and an elective course targeting improvement of academic and related abilities and activities. A midsemester early warning system has all faculty members provide lists of students at risk and then contact each student at risk with recommendations to use OASIS, advisors, instructors, and other resources. Career planning and job placement for students and graduates was centralized and communication of opportunities was enhanced. Additionally, student readiness

Table 1. The Abbreviated Goals, Sample Metrics, and Outcomes of the Sample Metrics for Strategy 1: Enhance Pharmacy Student Abilities and Learning Through Curricular Innovation, Integration, Application and Assessment

\begin{tabular}{llc}
\hline Abbreviated Goals & \multicolumn{1}{c}{ Sample Target Metrics } & $\begin{array}{c}\text { Achievement of Target } \\
\text { Metric at 3 Years }\end{array}$ \\
\hline $\begin{array}{l}\text { Evidence-based, active learning } \\
\text { methods are used in courses }\end{array}$ & Effective active learning methods are used in all courses & Met \\
$\begin{array}{l}\text { The curriculum is well-coordinated and } \\
\text { well-sequenced }\end{array}$ & Progressive curricular development of important topics \\
$\begin{array}{l}\text { Graduates develop abilities and meet } \\
\text { outcomes }\end{array}$ & $\geq 95 \%$ of graduates pass NAPLEX & On Course \\
$\begin{array}{l}\text { Graduates develop distinctive and } \\
\text { competitive abilities }\end{array}$ & $\geq 20 \%$ of students participate in research activities & Met \\
$\begin{array}{l}\text { Assessment data are used to enhance the } \\
\text { program }\end{array}$ & $\begin{array}{c}\text { Comprehensive review of the curriculum and courses is } \\
\text { performed at least every 4 years }\end{array}$ & Exceeded \\
\hline
\end{tabular}

On Course: the outcome did not meet the target metric but was within 2 to $5 \%$ of meeting the target

Unknown/Needs Revision: the outcome was unknown due to lack data collection and/or a useful metric 


\section{American Journal of Pharmaceutical Education 2019; 83 (6) Article 6899.}

Table 2. The Abbreviated Goals, Sample Metrics, and Outcomes of the Sample Metrics for Strategy 2: Enhance Pharmacy Students' Academic and Professional Success

\begin{tabular}{lcc}
\hline Abbreviated Goals & Sample Target Metrics & $\begin{array}{c}\text { Achievement of Target } \\
\text { Metric at 3 Years }\end{array}$ \\
\hline $\begin{array}{l}\text { High quality is maintained in applications } \\
\text { and matriculations }\end{array}$ & The average pre-professional GPA $\geq 3.30$ & On Course \\
$\begin{array}{l}\text { Student retention and progression are } \\
\text { supported and enhanced }\end{array}$ & $\begin{array}{c}\text { Mid-semester early warning system identifies and } \\
\text { contacts all students at risk }\end{array}$ & Met \\
$\begin{array}{l}\text { Student career planning and graduate } \\
\text { placement are well supported }\end{array}$ & $\begin{array}{c}\text { Career development services are rated } \geq 4.0 \text { on a } \\
\text { 5-point scale by graduating students }\end{array}$ & On Course \\
\hline
\end{tabular}

for careers and postgraduate training and education was enhanced through elective coursework, on-campus speakers, and development of a list of faculty members who could serve as career path advisors. In their responses to the AACP Curriculum Assessment Survey question on the school providing access to guidance on career planning, the percent of graduating students (indicating effective guidance) increased from $46 \%$ to $54 \%$ up to $71 \%$ following these enhancements.

Strategy 3, to build, expand and sustain community service and scholarship, impacted the development and delivery of health care outreach activities by students and faculty members, the creation of a master of science/ fellowship and expansion of international master of science programs, and continued expansion of research and scholarship support, grants submitted, and publication and presentation of research and scholarship.

Strategy 4, to strengthen partnerships with internal and external constituencies to maximize Pacific's competitiveness, resulted in a marked increase in communications with external partners through monthly newsletters, social media, and on-campus and off-campus meetings with alumni and other major constituents. Additionally, student attendance at professional and scientific local, regional, and national meetings was supported by the school and has increased. Particularly noteworthy was the increase in students who participated in the presentation of research abstracts at professional and national scientific meetings.

Strategy 5, to recruit, develop, retain, and support exceptional faculty and staff members in fulfilling their roles and responsibilities, resulted in ongoing improvements in the facilities and technologies for students, staff members, preceptors, and faculty members. Additionally, the focus on professional development has been key for new and existing faculty and staff members in enhancing and keeping up with changes in their responsibilities and abilities. Following further discussion after approval of the strategic plan, staff members decided not to initiate a formal recognition system to provide annual awards or recognition based on performance.
In the context of Pacific 2020, the strategic plan led to the reallocation of resources in our programs (and leadership). This plan guided the establishment of two Master of Science programs, enhancements in the assessment program, and enhanced professional development opportunities for faculty members. This plan also helped guide fundraising for our strategies such as OASIS, an important service to our students in overcoming academic challenges, enhancing information on career options and opportunities, increasing scholarships, upgrading facilities, providing immediate needs for operating funds, and enhancing endowment funds for operations.

The overall impact of the strategic plan was also demonstrated in faculty responses on the AACP Curriculum Assessment Surveys. When asked if the school effectively employed strategic planning, the percent of faculty members who strongly agreed or agreed increased from $73 \%$ just prior to the development of the strategic plan to $80 \%$ after implementing this plan. Additionally, when asked if the school requested their input during the development of the current strategic plan, the percent of faculty members who strongly agreed or agreed increased from $89 \%$ to $97 \%$ over the same period.

\section{DISCUSSION}

Strategic planning is an important activity in higher education for directing the academic institution, unit, or program towards meeting its goals. Strategic planning acknowledges and builds upon the mission and vision to determine the priorities, strategies, desired outcomes, and resource allocation that are thought to be most important in continuous quality improvement for the institution, unit, or program. There are numerous methods of strategic planning, ${ }^{1-4}$ but they all contain similar major components, and there are very few reports related to strategic planning in pharmacy or higher education. ${ }^{1}$ Those fundamental elements of strategic planning appear to be direction, guidance, and support from leadership; broad-based involvement by key constituents (faculty and staff members, students, and external partners); collection, review, 


\section{American Journal of Pharmaceutical Education 2019; 83 (6) Article 6899.}

analysis and use of pertinent information and data; and review and approval of the plan by major constituents. There are fewer reports in the literature describing what processes are needed after approval of the strategic plan, particularly with respect to monitoring and reviewing progress and determining the need for potential revisions.

We used a strategic planning model that had full involvement and acceptance by faculty members as well as other key groups (staff members, students, and external partners). Our planning process was designed to meet a fundamental component of strategic planning of being inclusive in nature, where all faculty members, alumni, and leadership participated in the development of the plan at multiple stages. Sharing our organization of and approach to the strategic planning process with all key players within the university at the beginning of the project distinguished our method from that described by others working in a complex academic environment like ours. ${ }^{10}$ Early involvement and communication was a key fundamental component used in our strategic planning process. This strategic plan was implemented and helped guide resource allocation and a comprehensive spectrum of activities at the school. The overall strengths and uniqueness of our strategic planning process was its comprehensive approach, use of a core strategic plan organizing committee, involvement of major stakeholders, and ongoing monitoring and assessment of progress.

The development and approval of the strategic plan are first steps towards the path of meeting the important goals of the academic institution, unit, or program. The next steps include the widespread communication of the strategic plan and implementation of the plan. Our strategic plan was disseminated to a broad audience, including the university leadership and administration, school faculty and staff, program students and alumni, and external partners including current and potential donors. It was not placed on the school or program webpage, but in retrospect that may have enhanced its dissemination.
Strategies were implemented in multiple ways. Efforts to enhance fund raising, community health care outreach, and enhancing student services were overt and very intentional. Efforts to enhance curricular delivery, scholarship and research, and faculty and staff development were more subtle, but still very apparent.

Monitoring and discussion of progress in meeting strategic goals and potential revisions were the next major steps. How progress would be monitored and reviewed was not initially clear to all faculty members, most likely because of the complexity of the strategic plan and some lack of clarity on how progress was to be assessed on each of those strategic goals. Once the progress was reviewed within the context of the strategic plan, the relationship of the progress to the strategic plan and the importance and value of the strategic plan became more evident to faculty members. However, the discussion, monitoring, and review of progress did not systematically include all elements of the strategic plan. A formal review of all the major strategies, goals, and metrics was only performed in preparation for the next strategic plan.

The assessment of the metrics used to determine progress on the strategic goals also provided insights into the design, utility, meaningfulness and measurability of the metrics. A few strategic goals and/or metrics were no longer relevant and other metrics were either not measured or the data collected were not consistent with the metric that was created in the strategic plan. For example, the first goal in strategy 2 was to assure high-quality applicants for the PharmD program, which included an aspirational metric as a pre-professional GPA of 4.0 and an achievable metric as a GPA of 3.0. However, our history showed a GPA of $>3.30$ would be more meaningful (Table 2) since over $95 \%$ of our matriculated students exceeded that metric. An example of an initial metric with built-in challenges was associated with strategy 3 in providing health care outreach to the community. The metric envisioned that $>50 \%$ of those served would come from

Table 3. The Abbreviated Goals, Sample Metrics, and Outcomes of the Sample Metrics for Strategy 3: Build, Expand and Sustain Community Service and Scholarship

\begin{tabular}{|c|c|c|}
\hline Abbreviated Goals & Sample Target Metrics & $\begin{array}{c}\text { Achievement of Target } \\
\text { Metric at } 3 \text { Years }\end{array}$ \\
\hline $\begin{array}{l}\text { Health care outreach is provided } \\
\text { to the community }\end{array}$ & $\begin{array}{l}\geq 50 \% \text { of those served by health care outreach are from } \\
\text { underserved populations }\end{array}$ & Unknown/Needs revision \\
\hline $\begin{array}{l}\text { Postgraduate programs are } \\
\text { expanded }\end{array}$ & $\begin{array}{l}\geq 2 \text { postgraduate education or training programs are evaluated } \\
\text { for development over next } 5 \text { years }\end{array}$ & Met \\
\hline $\begin{array}{l}\text { Faculty research and scholarship } \\
\text { is enhanced }\end{array}$ & $\geq 50 \%$ of tenure track faculty publish each year & Met \\
\hline
\end{tabular}




\section{American Journal of Pharmaceutical Education 2019; 83 (6) Article 6899.}

Table 4. The Abbreviated Goals, Sample Metrics, and Outcomes of the Sample Metrics for Strategy 4: Strengthen Partnerships with Internal and External Constituencies to Maximize Pacific's Competitiveness

\begin{tabular}{|c|c|c|}
\hline Abbreviated Goals & Sample Target Metrics & $\begin{array}{c}\text { Achievement of Target } \\
\text { Metric at } 3 \text { Years }\end{array}$ \\
\hline $\begin{array}{l}\text { Relationships with organizations and partners } \\
\text { are strong }\end{array}$ & $\geq 25 \%$ of students attend a state or national meeting & Unknown/Needs revision \\
\hline $\begin{array}{l}\text { Relationships with alumni and preceptors are } \\
\text { strong }\end{array}$ & $\begin{array}{l}\text { Preceptor development programs are rated at least } \\
4.0 \text { on a } 5 \text {-point scale by preceptors }\end{array}$ & Met \\
\hline $\begin{array}{l}\text { Communications with internal and external } \\
\text { constituents are effective }\end{array}$ & $\begin{array}{l}\text { Pertinent communications are disseminated to } \\
\quad \geq 90 \% \text { of available constituents }\end{array}$ & Unknown/Needs revision \\
\hline $\begin{array}{l}\text { The Pacific pharmacy brand image enhances } \\
\text { the School }\end{array}$ & $\begin{array}{l}\text { The Pacific pharmacy brand image is rated } \geq 4.0 \text { on } \\
\text { a 5-point scale by constituents }\end{array}$ & Unknown/Needs revision \\
\hline
\end{tabular}

underserved populations (Table 3). Unfortunately, it was difficult to collect the data and to ascertain whether each of those served came from an underserved population, considering the thousands of patients served at the many health care outreach events sponsored by the school. Although organizers of health outreach events believed that at least $50 \%$ of those served were from underserved populations, there were no data to document those impressions. Also within strategy 3 , "our graduate students will publish peer reviewed paper(s) under the advisor's guidance," is a metric that proved difficult to measure at a given time. Many research papers are typically published well after a student graduates, and consequently we need to revise this metric to state that "graduate students will publish peer-reviewed paper(s) within two years of graduation under the advisor's guidance." The data for several metrics described in Strategy 4 were also difficult to collect, including metrics related to relationships with organizations and partners, communications with constituents, and the brand image (Table 4).The lessons learned from this step is that early and planned timely review of all major strategies, strategic goals, and metrics is needed to fully assure the appropriate value and use of each ele- ment of the strategic plan. We recommend ensuring review of each major strategy, strategic goal, and metric by assigning responsibility centrally to a planning committee and/or decentralized to the administrative offices or committees associated with each element.

We propose the following guidelines to assist other pharmacy schools in creating an effective strategic plan. The strategic plan must be a living document with the ability to adapt to future trends, with assessment conducted early and systematically and necessary alterations to goals and metrics made in a timely manner. The plan should have clear goals, structure, and process set by the academic leader(s) and supported by faculty and staff members. To be effective, the strategic plan must be developed by a core group of planners drawn from all departments and key groups (staff, students, alumni, etc). An effective strategic plan should also involve essentially all faculty members in its development and then include adoption by the faculty as a whole and key representatives of staff, students, alumni, and external partners. The plan should contain strategies that cohesively focus on the most important areas. Additionally, the plan should include three to five specific goals for each strategy to

Table 5. The Abbreviated Goals, Sample Metrics, and Outcomes of the Sample Metrics for Strategy 5: Recruit, Develop, Retain, and Support Exceptional Faculty and Staff in Fulfilling Their Roles and Responsibilities

\begin{tabular}{lcc}
\hline Abbreviated Goals & Sample Target Metrics & $\begin{array}{c}\text { Achievement of Target } \\
\text { Metric at 3 Years }\end{array}$ \\
\hline $\begin{array}{l}\text { Faculty and staff evaluations support } \\
\text { development }\end{array}$ & All faculty and staff undergo evaluation in a timely manner & Met \\
$\begin{array}{l}\text { Faculty and staff are supported to } \\
\text { enhance their abilities }\end{array}$ & $\begin{array}{c}\geq 95 \% \text { of faculty and staff participate in } \geq 1 \\
\text { development opportunity each year }\end{array}$ & On Course \\
$\begin{array}{l}\text { Faculty and staff are rewarded for } \\
\text { outstanding accomplishments }\end{array}$ & $\begin{array}{c}\text { Faculty and staff with outstanding accomplishments } \\
\text { are formally recognized annually }\end{array}$ & $\begin{array}{c}\text { Faculty: Met } \\
\text { Staff: Unknown/Needs } \\
\text { Revision }\end{array}$ \\
$\begin{array}{lll}\text { Facilities, technologies and resources support } \\
\text { School personnel and students }\end{array}$ & $\begin{array}{c}\text { Students, faculty, preceptors and staff rate facilities } \\
\text { and technology at } \geq 4.0 \text { on a 5-point scale }\end{array}$ & Met \\
\hline
\end{tabular}




\section{American Journal of Pharmaceutical Education 2019; 83 (6) Article 6899.}

Table 6. Frequency and Percent of Achievement of the Target Metrics within Each Strategy Three Years After Approval and Implementation of the Strategic Plan

\begin{tabular}{lcccccc}
\hline & $\begin{array}{c}\text { Strategy 1 } \\
\text { No. (\%) }\end{array}$ & $\begin{array}{c}\text { Strategy 2 } \\
\text { No. (\%) }\end{array}$ & $\begin{array}{c}\text { Strategy 3 } \\
\text { No. (\%) }\end{array}$ & $\begin{array}{c}\text { Strategy 4 } \\
\text { No. (\%) }\end{array}$ & $\begin{array}{c}\text { Strategy 5 } \\
\text { No. (\%) }\end{array}$ & $\begin{array}{c}\text { Total, } \\
\text { No. (\%) }\end{array}$ \\
\hline Total Number of Metrics & 26 & 19 & 14 & 19 & 12 & 90 \\
Outcome Exceeded the Target & $7(27)$ & $5(26)$ & $6(43)$ & $1(5)$ & $2(17)$ & $21(23)$ \\
Outcome Met the Target & $12(46)$ & $3(16)$ & $5(36)$ & $2(11)$ & $7(58)$ & $29(32)$ \\
Outcome was "On Course" With the Target & $5(19)$ & $7(37)$ & $2(14)$ & $6(32)$ & $1(8)$ & $21(23)$ \\
Outcome Unknown and/or Needs Revision & $2(8)$ & $4(21)$ & $1(7)$ & $10(53)$ & $2(17)$ & $19(21)$ \\
\hline
\end{tabular}

provide focus for implementation. A strategic plan must include a sufficient number of measurable metrics to effectively evaluate the achievement of each strategy or goal. The plan should include continual communication of the strategies and progress in meeting strategic goals to all relevant participants. The plan must also include some strategies that can be accomplished in the near term and other strategies that take longer to accomplish. Finally, an effective strategic plan should provide guidance for resource generation and allocation.

\section{CONCLUSION}

A robust process involving all faculty members and key representatives from other constituencies was used to create a strategic plan in a school of pharmacy. The major challenges met in the planning process included full involvement and approval of faculty members and the creation of a strategic plan that was meaningful and led to enhancements in the vast majority of the strategic goals identified. Recommendations for other schools include making an early and sustained effort to monitor and review progress in an explicit manner, and incorporating a process for making revisions to major strategies, strategic goals, and/or metrics when appropriate. While strategic planning can be very effective in providing a platform for continuous improvement, a strategic plan should also be considered a "living" document that can be revised and refreshed.

\section{ACKNOWLEDGMENTS}

We express our sincere gratitude to all our faculty and staff, especially the other strategic planning committee members: Mamoun Alhamadsheh, Susan Burkhardt, Sean Carr-Lopez, Nancy DeGuire, Rajul Patel, Roshanak Rahimian, and Mark Walberg.

\section{REFERENCES}

1. Mintzberg H, Ahlstrand B, Lampel J. Strategy Safari: A Guide Tour Through the Wilds of Strategic Management. 1st ed. New York, NY: Free Press; 1998.

2. Allison M, Kaye J. Strategic Planning for Nonprofit Organizations: A Practical Guide and Workbook. 2nd ed. Hoboken, NJ: John Wiley \& Sons; 2005.
3. Rowley DJ, Sherman H. From Strategy to Change: Implementing the Plan in Higher Education. 1st ed. Hoboken, NJ: Jossey-Bass; 2001. 4. Kroboth P. Viewpoints: Planning strategically. Am J Pharm Educ. 2010;74(1):Article 2.

5. Holmes J. 20/20 Planning: The Story of the First Twenty Years of the Society for College and University Planning. Ann Arbor, MI:

Society for College and University Planning, 1985. https://www.scup.org/ page/resources/books/ttp. Accessed October 4, 2017.

6. Keller G. Academic Strategy: The Management Revolution in American Higher Education. Baltimore, MD: John Hopkins University Press, 1983.

7. Tromp SA, Ruben BD. Strategic Planning in Higher Education: A Guide for Leaders. $2^{\text {nd }}$ ed. Washington, DC: National Association of College and University Business Officers, 2010.

8. Sevier RA. Strategic Planning in Higher Education: Theory and Practice. $1^{\text {st }}$ ed. Washington, DC: CASE Books, 2001.

9. Accreditation Standards and Key Elements for the Professional Program in Pharmacy Leading to the Doctor of Pharmacy Degree: ("Standards 2016"). Accreditation Council for Pharmacy Education. https://www.acpe-accredit.org/pdf/Standards2016FINAL.pdf. Accessed October 4, 2017.

10. Hall PD, DiPiro JT, Rowen RC, McNair D. A continuous quality improvement program to focus a college of pharmacy on programmatic advancement. Am J Pharm Educ. 2013;77(6):Article 117.

11. Nahata M, Kelley K, McAuley J, Bennett M, Carnes C, Casper K, Knoell D, Pruchnicki M, Schneider P, Massaro A. Renewing vision and strategic priorities for an academic unit. Am J Pharm Educ. 2010;74(1):Article 13.

12. Poirier TI, Newman K. Advancing interprofessional education via strategic planning. Am J Pharm Educ. 2016;80(4):Article 56. 13. Knapp DA, Roffman DS, Cooper WJ. Growth of a pharmacy school through planning, cooperation, and establishment of a satellite campus. Am J Pharm Educ. 2009;73(6):Article 102.

14. Thompson ME, Harver A, Eure M. A model for integrating strategic planning and competence-based curriculum design in establishing a public health programme: the UNC Charlotte experience. Hum Resourc Health. 2009; 7:71. DOI: 10.1186/14784491-7-71.

15. Liffs L, Merkley J, Jeffrey J, Ferris E, Dusek J, Hunter C. Case study: reconciling the quality and safety gap through strategic planning. Nurs Leadership. 2006;19(2):32-40.

16. Higginbotham EJ, Kathryn C. Church KC. Strategic planning as a tool for achieving alignment in academic health centers. Trans Am Clin Climatol Assoc. 2012;123:292-303.

17. Levinson W, Axler H. Strategic planning in a complex academic environment: lessons from one academic health center. Acad Med. 2007;82:806-811. DOI: 10.1097/ACM.0b013e3180d08d14. 